\title{
Formic Acid Electrooxidation by a Platinum Nanotubule Array Electrode
}

\author{
Eric Broaddus, ${ }^{1}$ Ann Wedell, ${ }^{2}$ and Scott A. Gold ${ }^{2}$ \\ ${ }^{1}$ Institute for Micromanufacturing, Louisiana Tech University, Ruston, LA 71272, USA \\ ${ }^{2}$ Chemical and Materials Engineering Department, University of Dayton, Dayton, OH 45469, USA \\ Correspondence should be addressed to Scott A. Gold; sgold1@udayton.edu
}

Received 18 February 2013; Accepted 20 March 2013

Academic Editor: Benjamín R. Scharifker

Copyright (c) 2013 Eric Broaddus et al. This is an open access article distributed under the Creative Commons Attribution License, which permits unrestricted use, distribution, and reproduction in any medium, provided the original work is properly cited.

\begin{abstract}
One-dimensional metallic nanostructures such as nanowires, rods, and tubes have drawn much attention for electrocatalytic applications due to potential advantages that include fewer diffusion impeding interfaces with polymeric binders, more facile pathways for electron transfer, and more effective exposure of active surface sites. 1D nanostructured electrodes have been fabricated using a variety of methods, typically showing improved current response which has been attributed to improved CO tolerance, enhanced surface activity, and/or improved transport characteristics. A template wetting approach was used to fabricate an array of platinum nanotubules which were examined electrochemically with regard to the electrooxidation of formic acid. Arrays of 100 and $200 \mathrm{~nm}$ nanotubules were compared to a traditional platinum black catalyst, all of which were found to have similar surface areas. Peak formic acid oxidation current was observed to be highest for the $100 \mathrm{~nm}$ nanotubule array, followed by the $200 \mathrm{~nm}$ array and the Pt black; however, $\mathrm{CO}$ tolerance of all electrodes was similar, as were the onset potentials of the oxidation and reduction peaks. The higher current response was attributed to enhanced mass transfer in the nanotubule electrodes, likely due to a combination of both the more open nanostructure as well as the lack of a polymeric binder in the catalyst layer.
\end{abstract}

\section{Introduction}

Nanostructured materials have long been used in catalysis, usually in the form of metallic nanoparticles on high surface area supports with nanoscale porosity. More recently, onedimensional metallic nanostructures such as nanowires, rods, and tubes have drawn attention for such electrocatalytic applications, including fuel cells and electrochemical sensors. These types of structures present many potential advantages, including fewer diffusion impeding interfaces with polymeric binders, more facile pathways for electron transfer, and more effective exposure of active surface sites. Such $1 \mathrm{D}$ metallic nanostructures have been fabricated by a variety of methods, including template-based methods (wetting [1-4] and electrosynthesis or electrodeposition [5-11]), electrospinning [12], deposition onto nanowire or nanofiber supports [1315], and others [16-19]. To date, most studies of these nanomaterials have focused on demonstrating the viability of the nanofabrication process and describing fundamental material properties such as morphology, composition, and crystal structure with far less attention paid to their functional properties.

Electrocatalytic studies of $1 \mathrm{D}$ metal nanostructures have focused on small organic molecules, in particular those important to fuel cell applications such as methanol $[7,8$, $11,20,21]$ and formic acid $[19,22-25]$. Often, such studies are only cursory merely demonstrating some degree of electrocatalytic activity with no comparison to a standard catalyst or quantification of kinetic parameters, with the focus being on the fabrication process and other material properties [7]. When electrochemical activity has been the focus, higher current response has typically been reported from 1D nanostructures in comparison to commercial catalysts. The cause of this improved performance has been attributed to different factors, including enhanced catalytic activity of the nanostructured surface, improved CO tolerance, and faster transport in the catalyst layer. Higher catalytic activity has been reported for Pt nanowires made by electrodeposition 


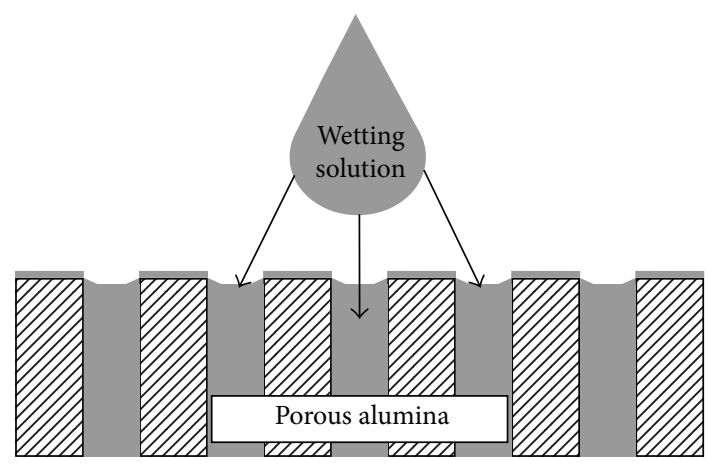

(a)

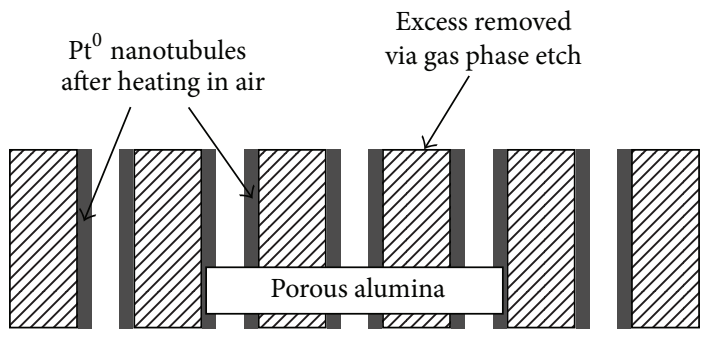

(c)

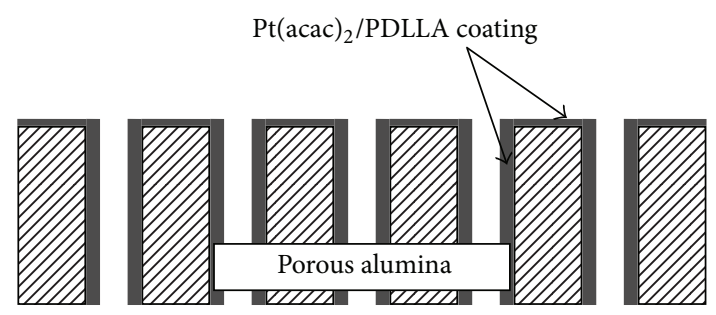

(b)

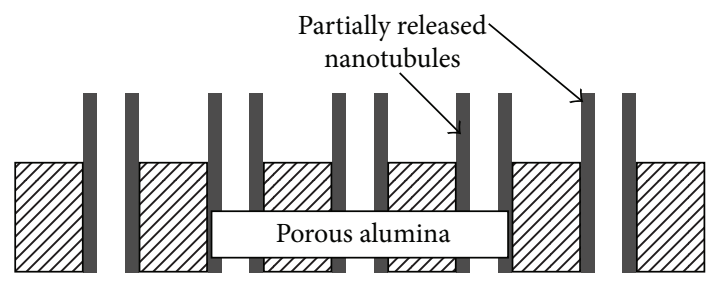

(d)

FIGURE 1: Overview of the template wetting nanofabrication process for making a platinum nanotubule array. (a) A porous alumina template is wetted with a solution of $\mathrm{Pt}(\mathrm{acac})_{2}$ and PDLLA in chloroform. (b) After evaporation of the solvent, a solid Pt(acac) 2 /PDLLA coating remains on the pore walls of the template. (c) A helium plasma etch is used to remove excess material on the outer surfaces, after which samples are annealed in air to reduce the $\mathrm{Pt}(\mathrm{acac})_{2}$ to $\mathrm{Pt}^{0}$ as well as to oxidize and remove the PDLLA. (d) The resulting Pt nanotubes were partially released by selectively etching the alumina template in $25 \mathrm{wt}$ \% $\mathrm{KOH}(\mathrm{aq})$ for $2 \mathrm{~min}$.

in a polymeric template for methanol electrooxidation [21] and for porous Pt nanowires made by electrodeposition in an alumina template for ethanol electrooxidation [26] in comparison to a commercial Pt black catalyst. In contrast, poorer activity was reported for methanol electrooxidation with PtRu nanowire networks fabricated by electrodeposition in an SBA-15 in comparison to a commercial PtRu black, though with greater power output from a resulting fuel cell attributed to enhanced mass transport of products and reactants in the porous network and reduced the number of interfaces from the lack of a Nafion binder commonly used with Pt black catalysts [11]. Lower activity was also reported for methanol oxidation with Pt nanowires produced via an electrospinning process though with greater $\mathrm{CO}$ tolerance than a commercial Pt black catalyst [12].

For this work, platinum nanotubules formed via a simple template-based wetting process, previously demonstrated by Steinhart et al. $[1,3,27]$, will be compared with a traditional platinum black catalyst for formic acid electrooxidation. Template wetting is arguably among the simplest nanofabrication technologies and results in an aligned array of nanotubules amenable to use in a number of devices, including small-scale fuel cells and electrochemical sensors. The process utilizes surface tension to draw a solution containing a metal precursor into the pores of a template. The precursor coats the pore walls of the template and is subsequently reduced to form metal nanotubules. Material properties of Pt nanotubules made in the manner have been previously reported [3]. The focus of this work is on the electrochemical performance of these nanostructures toward formic acid electrooxidation. Formic acid was chosen for this study due in part to its promise in direct formic acid fuel cells which have emerged as a key challenger to direct methanol technologies in recent years [28-31] but also due to its long serving role as a model for the electrooxidation for other small organic molecules [32-36].

\section{Experimental}

2.1. Fabrication of Platinum Nanotubule Array Electrode. Platinum nanotubule arrays were fabricated via template wetting [3] using porous alumina membranes (Whatman, Anodisc, $60 \mu \mathrm{m}$ thick with either 100 or $200 \mathrm{~nm}$ nominal pore diameters containing pore densities of $10^{10}$ and $10^{9}$ pores $/ \mathrm{cm}^{2}$, resp.) as templates. The nanofabrication process, illustrated in Figure 1, involved wetting these templates with a solution prepared by mixing platinum (II) 2,4-pentanedionate $\left(\mathrm{Pt}(\mathrm{acac})_{2}\right)$ (Alfa Aesar) and poly(D,Llactide) (PDLLA) (Sigma-Aldrich) in a 3:1 ratio in chloroform (Acros Organics, ACS Reagent) to a final concentration of $66.6 \mathrm{mg} \mathrm{Pt}(\mathrm{acac})_{2} / \mathrm{mL}$. Using the given nominal pore diameter and density along with the bulk density of platinum and the assumption that all solution entered the pores and that the pores were cylindrical, sufficient solution was pipetted onto the template to form $5 \mathrm{~nm}$ thick 


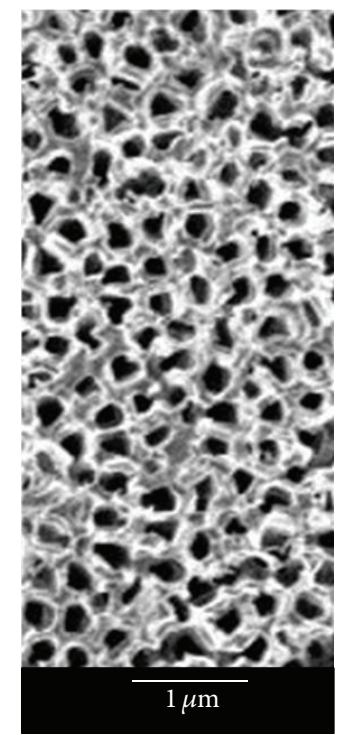

(a)

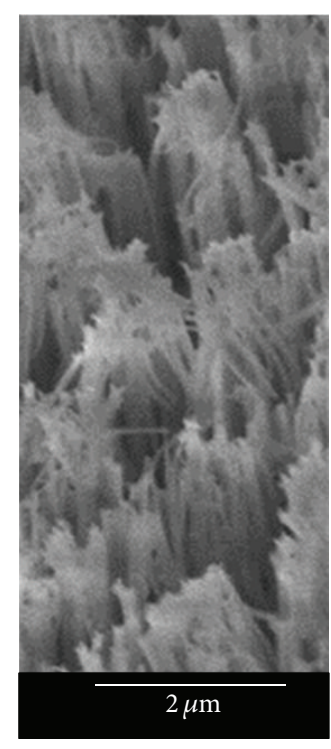

(b)

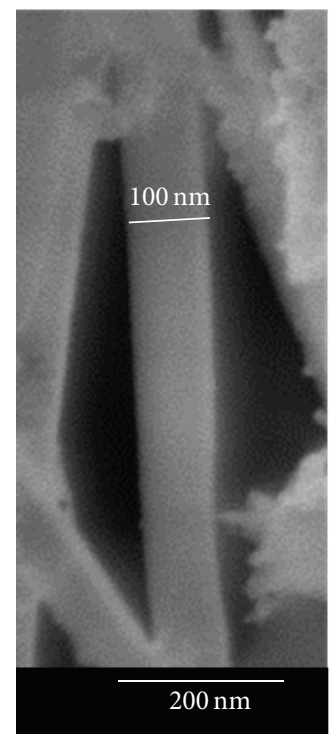

(c)

FIGURE 2: SEM images showing (a) the template surface before helium plasma and $\mathrm{KOH}$ etcht steps, (b) an array $100 \mathrm{~nm}$ Pt nanotubules, and (c) a close-up image of an individual $100 \mathrm{~nm}$ Pt nanotubule.

tubule walls. The solution was observed to readily wet the template and allowed to dry in air for $24 \mathrm{hrs}$, leaving a solid $\mathrm{Pt}(\mathrm{acac})_{2} /$ PDLLA film coating the pore walls of the template after solvent evaporation. Residual material on the external surfaces of the templates was removed using a helium plasma etch (200 mTorr, for $10 \mathrm{~min}$ ) in a Plasma-Therm RIE system. Samples were then annealed in air at $200^{\circ} \mathrm{C}$ for $24 \mathrm{hrs}$, followed by $1 \mathrm{hr}$ at $350^{\circ} \mathrm{C}$ to reduce the $\mathrm{Pt}(\mathrm{acac})_{2}$ to $\mathrm{Pt}^{0}$ as well as to oxidize and remove the PDLLA [3]. The resulting Pt nanotubes were partially released by selectively etching the alumina template in 25 wt. $\% \mathrm{KOH}(\mathrm{aq})$ for 2 min followed by rinsing in DI water. These were inspected visually using a Hitachi S-4800 field emission SEM.

Electrochemical characterization of the Pt nanotubule array was carried out by attaching it to a polished glassy carbon electrode ( $3 \mathrm{~mm}$, encased in Kel-F, CH Instruments) using an alcohol-based conductive graphite adhesive (Alfa Aesar product no. 42466). For comparison purposes, a traditional platinum black material (HiSPEC 1000, Alfa Aesar) was also evaluated. The Pt black was dispersed in DI water and Nafion (5 wt.\%, Solution Technology, Inc.) to a final concentration of $2 \mathrm{mg} \cdot \mathrm{mL}^{-1}$ Pt with $10 \%$ Nafion by mass, pipetted onto the same polished glassy electrode surface, and allowed to dry in air at room temperature for $24 \mathrm{hrs}$.

\subsection{Electrochemical Characterization. All electrochemical} tests were carried out with a Gamry Instruments PCI4 Potentiostat using a traditional three-electrode cell using a Pt nanotubule array or Pt black working electrode as described above, a platinum wire counter electrode, and an $\mathrm{Ag} / \mathrm{AgCl}$ reference electrode ( $\mathrm{CH}$ Instruments), though all potentials in this work are reported relative to the standard hydrogen electrode (SHE). The solutions used in the electrochemical cell were deaerated by bubbling $\mathrm{N}_{2}$ gas and the cell was subsequently blanketed with $\mathrm{N}_{2}$ during the experimental procedure. The Pt catalyst structures were cleaned electrochemically by cycling the potential between $1.5 \mathrm{~V}$ and $0.03 \mathrm{~V}$ versus SHE (standard hydrogen electrode) at a scan rate of $500 \mathrm{mV} / \mathrm{s}$ in a $0.5 \mathrm{M} \mathrm{H}_{2} \mathrm{SO}_{4}$ (aq) solution (GFS Chemicals, Veritas Grade, double distilled in $18 \mathrm{M} \Omega$ deionized water) until a steady-state voltammogram was obtained (approximately 50 cycles) prior to analysis [37, 38]. Active surface area was evaluated using the hydrogen adsorption peaks in the voltammograms from this same solution. Integration of these peaks with respect to time and subtraction of the background double layer charge provides the charge due to hydrogen adsorption $[33,39]$. Using a value $210 \mu \mathrm{C} / \mathrm{cm}^{2}$ for the deposition of a monolayer of hydrogen on a Pt surface allows the surface area to be calculated [39]. To evaluate formic acid electrooxidation kinetics, formic acid (GFS Chemicals, Veritas Grade, double distilled) was added to the $0.5 \mathrm{M} \mathrm{H}_{2} \mathrm{SO}_{4}$ (aq) supporting electrolyte to a concentration of $0.25 \mathrm{M} \mathrm{HCOOH}$ for both cyclic voltammetry and chronoamperometry experiments.

\section{Results and Discussion}

3.1. Structure and Surface Area. Representative scanning electron micrographs of $\mathrm{Pt}$ nanotubules are shown in Figure 2. The template is shown prior to the $\mathrm{KOH}$ etching step in Figure 2(a) with the lumen of the nanotubules visible. Figures 2(b) and 2(c) show the exposed nanotubules after the template is partially removed. The high yield of the fabrication process, approximately one tubule per template pore, and the alignment of the tubules are readily apparent in Figure 2(b). As expected, tubule diameter is consistent with the template pore diameter, as shown for tubules made using the $100 \mathrm{~nm}$ pore diameter template in Figure 2(c). 
The active surface areas of platinum in electrodes made from the nanotubules as well as for a more traditional platinum black described above were evaluated using cyclic voltammetry in $0.5 \mathrm{M}$ sulfuric acid. Representative voltammograms are shown in Figure 3 with the hydrogen adsorption region highlighted. Qualitatively, these appear consistent with the expected form for a platinum electrode with hydrogen adsorption/oxidation and platinum oxide formation/reduction peaks clearly observable [39]. Integration of the hydrogen adsorption peaks to give the charge due to hydrogen adsorption was used to determine surface areas of 19.5 and $14.7 \mathrm{~m}^{2} / \mathrm{g}$ of Pt for the 100 and $200 \mathrm{~nm}$ Pt nanotubules. Total platinum loading based on the total amount of metal in the wetting solution was $0.8 \mathrm{mg} / \mathrm{cm}^{2}$ for these samples. Actual loading should be somewhat lower as some material was removed in the helium plasma etching step of the fabrication process. The platinum black provided a slightly higher surface area of $20.4 \mathrm{~m}^{2} / \mathrm{g}$ at a loading of $0.5 \mathrm{mg} / \mathrm{cm}^{2}$. This value is somewhat lower than that reported by the manufacturer of $27 \mathrm{~m}^{2} / \mathrm{g}$ due to the presence of the Nafion binder in the catalyst ink.

3.2. Cyclic Voltammetry. Figure 4 shows representative cyclic voltammograms of the 100 and $200 \mathrm{~nm}$ Pt nanotubular catalysts and Pt black catalyst ink for the electrooxidation formic acid, collected using an $0.25 \mathrm{M} \mathrm{HCOOH}$ in an $0.5 \mathrm{M} \mathrm{H}_{2} \mathrm{SO}_{4}$ supporting electrolyte. These are in qualitative agreement with the expected form for the electrooxidation of formic acid on a Pt catalyst [33,37, 40,41]. The hydrogen adsorption/desorption peaks between 0.05 and $0.4 \mathrm{~V}$ versus SHE are suppressed compared to those observed in Figure 3 due to the adsorption of $\mathrm{CO}[20,33,35,40]$. Anodic peaks associated with the oxidation of $\mathrm{HCOOH}$ and $\mathrm{CO}$ are observed at $\sim 0.5$ and $\sim 0.9 \mathrm{~V}$ versus SHE, respectively, along with a broad cathodic peak stretching from $\sim 0.7$ to $0.4 \mathrm{~V}$ due to the oxidation of formic acid after the reduction of the surface Pt oxides [20,35,40]. The cathodic scan where the surface has been cleaned of absorbed CO and surface oxides thus represents the real catalytic activity of the Pt surface [40]. Comparing the maximum current of the cathodic formic acid oxidation peak normalized to the active surface area reveals that the $100 \mathrm{~nm}$ Pt nanotubules exhibit the highest apparent activity toward formic acid electrooxidation followed by the $200 \mathrm{~nm}$ nanotubules and the Pt black ink.

Previous studies have reported improved CO tolerance in 1D metal nanostructures used as catalysts for methanol electrooxidation $[7,11,12,15]$. As noted previously, the first anodic peak at $\sim 0.5 \mathrm{~V}$ versus SHE is due to formic acid oxidation on a surface partially covered by $\mathrm{CO}$, while the large cathodic peak results from the same reaction on a clean Pt surface. The ratio of the maximum current densities of these two peaks provides a measure of the fraction of the catalyst surface not poisoned by $\mathrm{CO}$ adsorption and is hence a measure of the $\mathrm{CO}$ poison resistance $[20,42]$. Values of this ratio, $j_{a 1} / j_{c 1}$, are $0.27,0.26$, and 0.27 for the $100 \mathrm{~nm}$ nanotubules, $200 \mathrm{~nm}$ nanotubules, and Pt black catalysts, respectively, indicating no significant difference in $\mathrm{CO}$ tolerance between the three catalysts. This

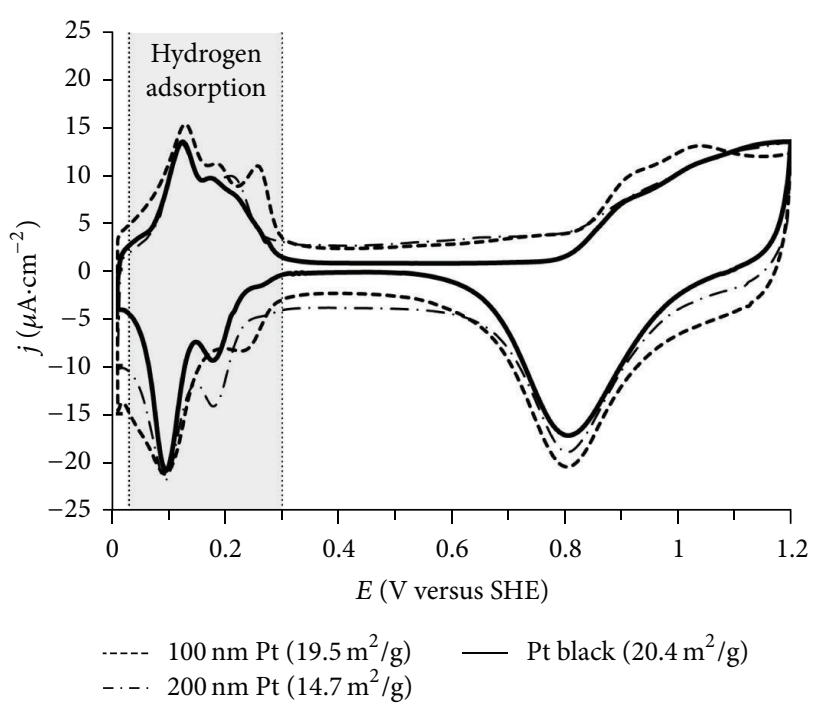

Figure 3: Cyclic voltammograms of $100 \mathrm{~nm}$ and $200 \mathrm{~nm}$ Pt nanotubule electrodes and a Pt black electrode with $10 \mathrm{wt} . \%$ Nafion in $0.5 \mathrm{M} \mathrm{H}_{2} \mathrm{SO}_{4}$ (aq) at $15 \mathrm{mV} / \mathrm{s}$. The highlighted hydrogen adsorption region was used to determine active surface areas, shown in the legend.

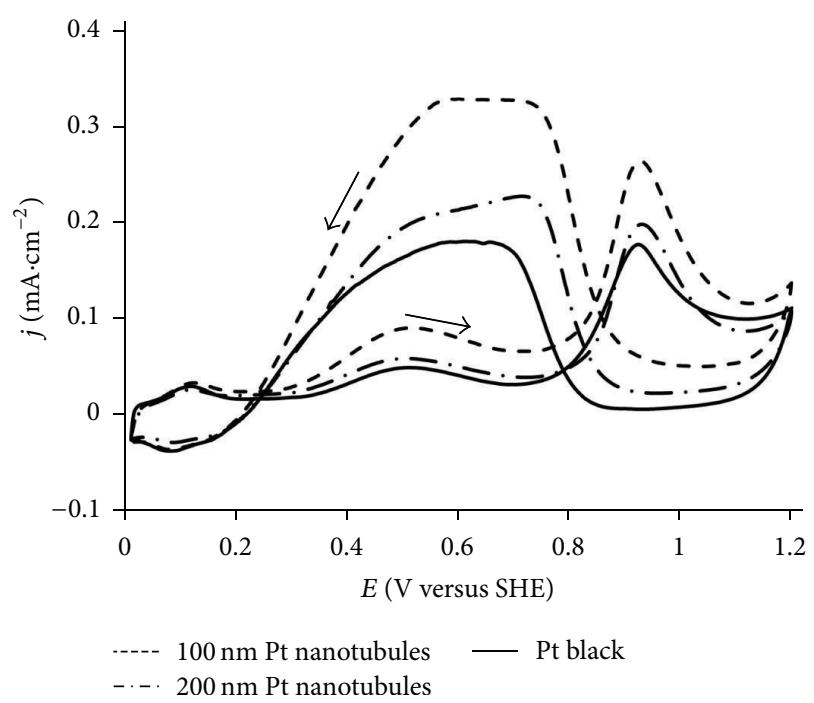

FIGURE 4: Cyclic voltammogram profiles for the electro-oxidation of formic acid $\left(0.25 \mathrm{M} \mathrm{HCOOH}\right.$ in $\left.0.5 \mathrm{M} \mathrm{H}_{2} \mathrm{SO}_{4}, 50 \mathrm{mV} / \mathrm{s}\right)$ on the $100 \mathrm{~nm}$ Pt nanotubule, $200 \mathrm{~nm}$ Pt nanotubule, and the Pt black electrodes.

is a contrast with results for other types of $1 \mathrm{D}$ nanostructures $[7,11,12,15]$.

Figure 5(a) shows cyclic voltammograms for the $100 \mathrm{~nm}$ Pt nanotubule electrode at scan rates from 1 to $100 \mathrm{mV} / \mathrm{s}$. The maximum current for the cathodic formic acid oxidation peak was then plotted in Figure 5(b) versus the square root of the scan rate which is expected to be linear for a diffusion controlled reaction, as is expected and observed here. The slope of the best fit line was largest for the $100 \mathrm{~nm}$ nanotubule electrode, followed by the $200 \mathrm{~nm}$ nanotubules 


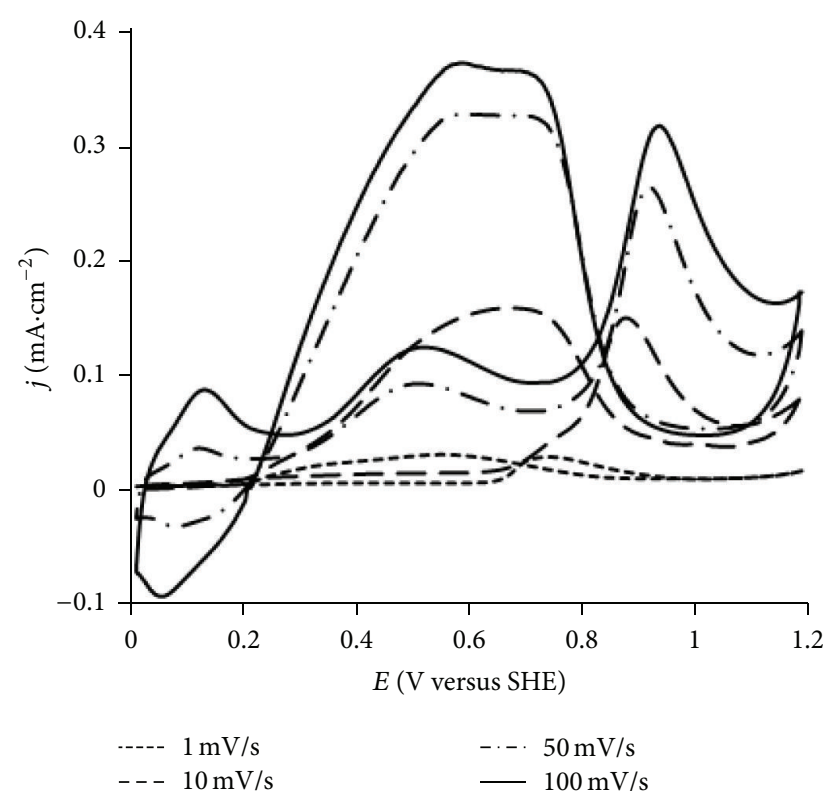

(a)

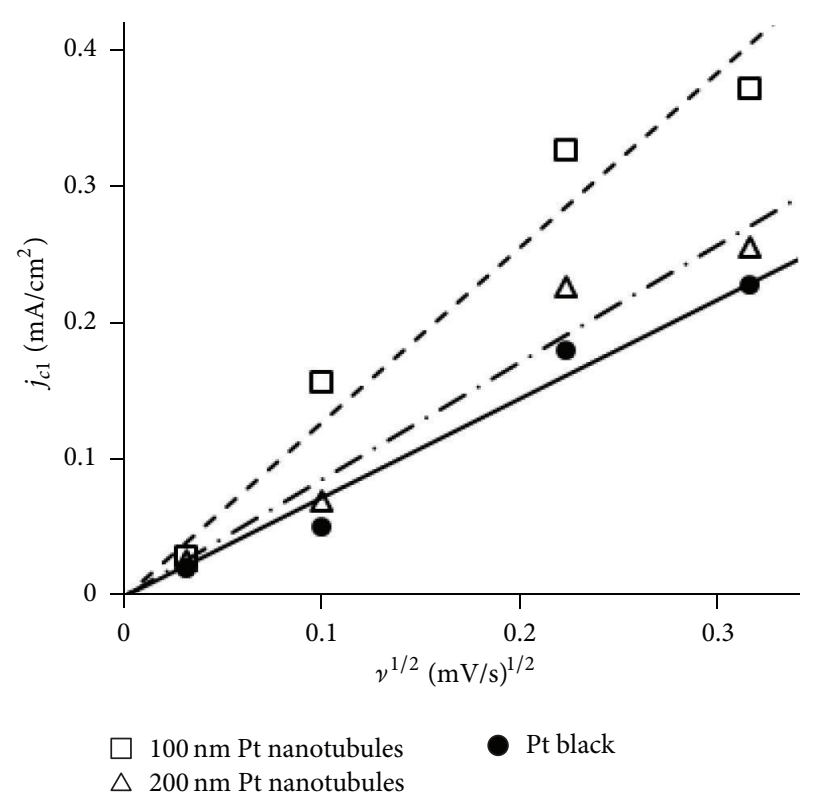

(b)

Figure 5: (a) Cyclic voltammograms for the electro-oxidation of formic acid $\left(0.25 \mathrm{M} \mathrm{HCOOH}\right.$ in $\left.0.5 \mathrm{M} \mathrm{H}_{2} \mathrm{SO}_{4}\right)$ on the $100 \mathrm{~nm} \mathrm{Pt}$ nanotube at 1, 10, 50, and $100 \mathrm{mV} / \mathrm{s}$. (b) Cathodic formic acid oxidation peak current versus square root of scan rate for $100 \mathrm{~nm} \mathrm{Pt}$ nanotubule, $200 \mathrm{~nm} \mathrm{Pt}$ nanotubule, and Pt black electrodes. Trendlines represent a linear regression best fit of the data with $R^{2}$ values of 0.95 , 0.96 , and 0.97 , respectively.

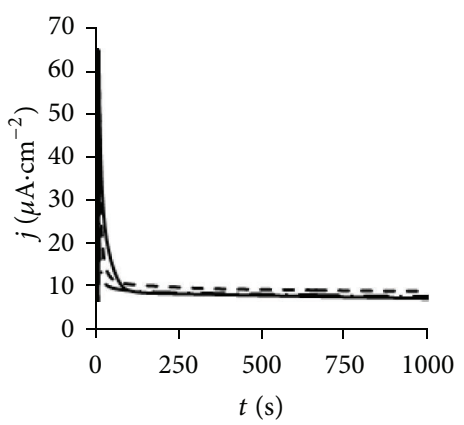

----- $100 \mathrm{~nm}$ Pt nanotubules

-... $200 \mathrm{~nm}$ Pt nanotubules - Pt black

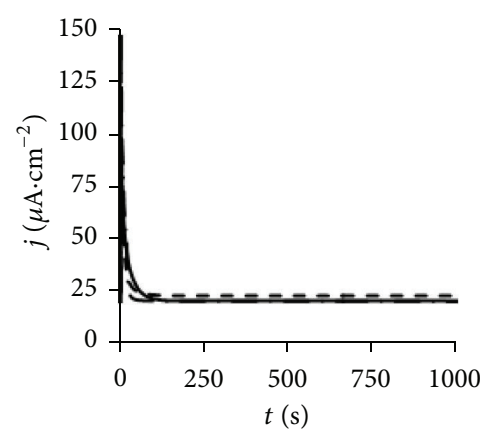

----- $100 \mathrm{~nm}$ Pt nanotubules

-. - $200 \mathrm{~nm}$ Pt nanotubules

_ Pt black

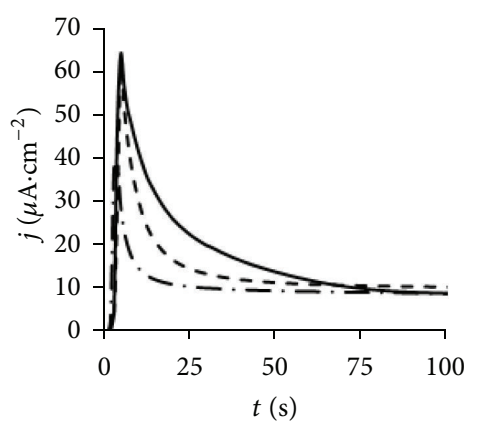

---- $100 \mathrm{~nm}$ Pt nanotubules

-.. $200 \mathrm{~nm}$ Pt nanotubules

— Pt black

(a) $0.400 \mathrm{~V}$ versus SHE

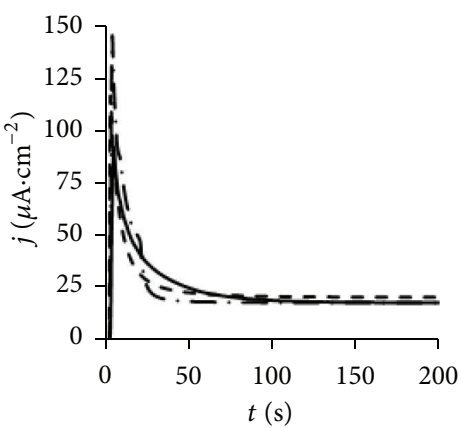

-.--- $100 \mathrm{~nm}$ Pt nanotubules

-. . $200 \mathrm{~nm}$ Pt nanotubules

_ Pt black

(b) $0.475 \mathrm{~V}$ versus SHE

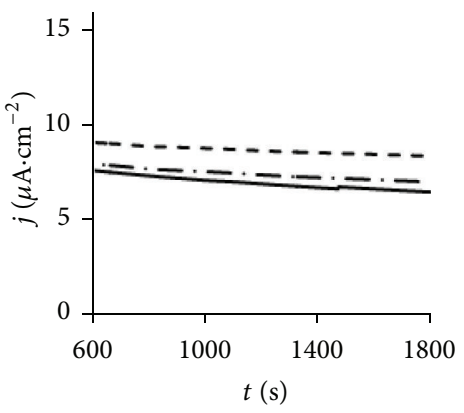

---- $100 \mathrm{~nm}$ Pt nanotubules

... $200 \mathrm{~nm}$ Pt nanotubules

— Pt black

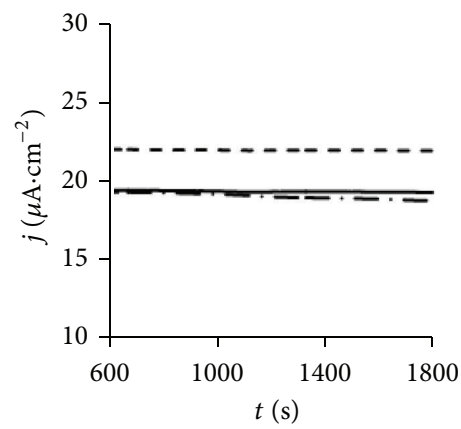

---- $100 \mathrm{~nm}$ Pt nanotubules

-.-. $200 \mathrm{~nm}$ Pt nanotubules

_ Pt black

Figure 6: Chronoamperometry data for the 100 and $200 \mathrm{~nm}$ Pt nanotube and the Pt black/10 wt\% Nafion catalyst in of $0.25 \mathrm{M}$ HCOOH in $0.5 \mathrm{M} \mathrm{H}_{2} \mathrm{SO}_{4}$ at (a) 0.400 and (b) $0.475 \mathrm{~V}$ versus SHE. The three plots at each voltage show different time scales to facilitate comparison. 
and the platinum black. The larger slope is indicative of a greater apparent diffusivity in the catalyst layer indicating that the increased activity observed is due at least in part to enhanced mass transport. The two anodic peaks showed the same trend when plotted in a similar manner to Figure 5(b). Enhanced mass transfer is consistent with results reported by Choi and Woo [11].

3.3. Chronoamperometry. Chronoamperometry results at 0.400 and $0.475 \mathrm{~V}$ versus SHE are illustrated in Figure 6 for the same formic acid solution. These potentials correspond to just after the onset of formic acid electrooxidation and near the peak current observed in the cyclic voltammograms. As is typical, the current declines rapidly after the voltage step is applied due to the accumulation of CO on Pt surface sites until some equilibrium surface coverage is reached. The initial current decline is more rapid for both nanotubule catalysts than for the platinum black. This observation is consistent either with a greater susceptibility to CO poisoning or with enhanced mass transfer of reactants to the surface allowing more rapid $\mathrm{CO}$ accumulation. As the $j_{a 1} / j_{c 1}$ ratio from the $\mathrm{CV}$ data discussed previously indicates similar CO tolerance for all three electrodes, the latter conclusion appears more likely. The steady current density at longer times is also observed to be significantly higher for the $100 \mathrm{~nm}$ Pt nanotubules and even slightly higher for the $200 \mathrm{~nm}$ nanotubules in comparison with the Pt black, consistent with oxidation and reduction peak current trends observed in the cyclic voltammograms. While an enhanced rate constant or reduced $\mathrm{CO}$ coverage would yield this result, the data is also consistent with more rapid mass transport which is supported by the previously discussed voltammetry data.

\section{Conclusions}

Template wetting nanofabrication was successfully used to prepare an array of Pt nanotubules using porous alumina template. The process provided a high yield of nanotubules with geometry consistent with that expected from the porous template used and a high surface area comparable to that of a typical Pt black catalyst ink based on a commercial catalyst. The ease of fabrication and resulting nanotubule array structure should be suitable for a number of sensor or small fuel cell applications. The highest current response for formic acid electrooxidation was observed from the $100 \mathrm{~nm}$ nanotubules followed by the $200 \mathrm{~nm}$ nanotubules and finally the commercial Pt black catalyst. The Pt nanotubules showed similar susceptibility to CO poisoning and inherent activity toward formic acid electrooxidation to a commercial Pt black. The increased current response was found to be the result of enhanced mass transfer in the more open nanotubule array structure with no polymeric binder such as the Nafion commonly used with Pt black.

\section{Conflict of Interests}

The authors of this paper do not have any direct financial relation with the commercial identities mentioned in their manuscript that might lead to a conflict of interests.

\section{Acknowledgment}

This work was funded in part by the Louisiana Board of Regents/RCS Program, Award LEQSF (2006-09)-RD-A-21.

\section{References}

[1] M. Steinhart, J. H. Wendorff, and R. B. Wehrspohn, "Nanotubes à la Carte: Wetting of Porous Templates," ChemPhysChem, vol. 4, no. 11, pp. 1171-1176, 2003.

[2] M. Steinhart, Z. Jia, A. K. Schaper, R. B. Wehrspohn, U. Gösele, and J. H. Wendorff, "Palladium nanotubes with tailored wall morphologies," Advanced Materials, vol. 15, no. 9, pp. 706-709, 2003.

[3] Y. Luo, S. K. Lee, H. Hofmeister, M. Steinhart, and U. Gösele, "Pt nanoshell tubes by template wetting," Nano Letters, vol. 4, no. 1, pp. 143-147, 2004.

[4] P. Göring, E. Pippel, H. Hofmeister, R. B. Wehrspohn, M. Steinhart, and U. Gösele, "Gold/carbon composite tubes and gold nanowires by impregnating templates with hydrogen tetrachloroaurate/acetone solutions," Nano Letters, vol. 4, no. 6 , pp. 1121-1125, 2004.

[5] Y. Piao, H. Lim, J. Y. Chang, W. Y. Lee, and H. Kim, "Nanostructured materials prepared by use of ordered porous alumina membranes," Electrochimica Acta, vol. 50, no. 15, pp. 2997-3013, 2005.

[6] M. Xu, Z. Zhang, and X. Yang, "Electrocatalytic oxidation of methanol on Pd nanowire electrode in alkaline media," Rare Metal Materials and Engineering, vol. 39, no. 1, pp. 129-133, 2010.

[7] S. M. Choi, J. H. Kim, J. Y. Jung, E. Y. Yoon, and W. B. Kim, "Pt nanowires prepared via a polymer template method: Its promise toward high Pt-loaded electrocatalysts for methanol oxidation," Electrochimica Acta, vol. 53, no. 19, pp. 5804-5811, 2008.

[8] K. S. Napolskii, P. J. Barczuk, S. Y. Vassiliev, A. G. Veresov, G. A. Tsirlina, and P. J. Kulesza, "Templating of electrodeposited platinum group metals as a tool to control catalytic activity," Electrochimica Acta, vol. 52, no. 28, pp. 7910-7919, 2007.

[9] Y. J. Song, S. B. Han, and K. W. Park, "Pt nanowire electrodes electrodeposited in PVP for methanol electrooxidation," Materials Letters, vol. 64, no. 18, pp. 1981-1984, 2010.

[10] F. Cheng, X. Dai, H. Wang, S. P. Jiang, M. Zhang, and C. Xu, "Synergistic effect of Pd-Au bimetallic surfaces in Au-covered Pd nanowires studied for ethanol oxidation," Electrochimica Acta, vol. 55, no. 7, pp. 2295-2298, 2010.

[11] W. C. Choi and S. I. Woo, "Bimetallic Pt-Ru nanowire network for anode material in a direct-methanol fuel cell," Journal of Power Sources, vol. 124, no. 2, pp. 420-425, 2003.

[12] J. M. Kim, H. I. Joh, S. M. Jo et al., "Preparation and characterization of Pt nanowire by electrospinning method for methanol oxidation," Electrochimica Acta, vol. 55, no. 16, pp. 4827-4835, 2010.

[13] X. S. He, C. G. Hu, and H. Liu, "Fabrication of 3D Pt catalysts via support of $\mathrm{Na}_{2} \mathrm{Ti}_{3} \mathrm{O}_{7}$ nanowires for methanol and ethanol electrooxidation," Catalysis Communications, vol. 12, no. 2, pp. 100-104, 2010.

[14] L. Su, W. Jia, A. Schempf, and Y. Lei, "Palladium/titanium dioxide nanofibers for glycerol electrooxidation in alkaline 
medium," Electrochemistry Communications, vol. 11, no. 11, pp. 2199-2202, 2009.

[15] S. Sun, G. Zhang, D. Geng et al., "Direct growth of single-crystal Pt nanowires on Sn@CNT nanocable: 3D electrodes for highly active electrocatalysts," Chemistry, vol. 16, no. 3, pp. 829-835, 2010.

[16] X. Gu, X. Cong, and Y. Ding, "Platinum-decorated Au porous nanotubes as highly efficient catalysts for formic acid electrooxidation," ChemPhysChem, vol. 11, no. 4, pp. 841-846, 2010.

[17] Z. X. Liang, J. Y. Shi, S. J. Liao, and J. H. Zeng, "Noble metal nanowires incorporated Nafion membranes for reduction of methanol crossover in direct methanol fuel cells," International Journal of Hydrogen Energy, vol. 35, no. 17, pp. 9182-9185, 2010.

[18] I. S. Park, J. H. Choi, and Y. E. Sung, "Synthesis of $3 \mathrm{~nm}$ Pt nanowire using MCM-41 and electrocatalytic activity in methanol electro-oxidation," Electrochemical and Solid-State Letters, vol. 11, no. 5, pp. B71-B75, 2008.

[19] X. Wang and Q. Jiang, "Developing nanoscale inertial measurement systems with carbon nanotube oscillators," Nanotechnology, vol. 19, no. 8, Article ID 085708, 2008.

[20] Y. Zhong, C. L. Xu, L. B. Kong, and H. L. Li, "Synthesis and high catalytic properties of mesoporous Pt nanowire array by novel conjunct template method," Applied Surface Science, vol. 255, no. 5, pp. 3388-3393, 2008.

[21] G. Y. Zhao, C. L. Xu, D. J. Guo, H. Li, and H. L. Li, “Template preparation of $\mathrm{Pt}-\mathrm{Ru}$ and $\mathrm{Pt}$ nanowire array electrodes on a Ti/Si substrate for methanol electro-oxidation," Journal of Power Sources, vol. 162, no. 1, pp. 492-496, 2006.

[22] H. Meng, S. Sun, J. P. Masse, and J. P. Dodelet, "Electrosynthesis of Pd single-crystal nanothorns and their application in the oxidation of formic acid," Chemistry of Materials, vol. 20, no. 22, pp. 6998-7002, 2008.

[23] J. Wang, Y. Chen, H. Liu, R. Li, and X. Sun, "Synthesis of Pd nanowire networks by a simple template-free and surfactantfree method and their application in formic acid electrooxidation," Electrochemistry Communications, vol. 12, no. 2, pp. 219222, 2010.

[24] C. Anastasescu, M. Anastasescu, M. Zaharescu, and I. Balint, "Platinum-modified $\mathrm{SiO}_{2}$ with tubular morphology as efficient membrane-type microreactors for mineralization of formic acid," Journal of Nanoparticle Research, vol. 14, article 1198, 2012.

[25] Y. Kim, H. J. Kim, Y. S. Kim, S. M. Choi, M. H. Seo, and W. B. Kim, "Shape- and composition-sensitive activity of Pt and PtAu catalysts for formic acid electrooxidation," Journal of Physical Chemistry C, vol. 116, no. 34, pp. 18093-18100, 2012.

[26] X. Zhang, W. Lu, J. Da, H. Wang, D. Zhao, and P. A. Webley, "Porous platinum nanowire arrays for direct ethanol fuel cell applications," Chemical Communications, no. 2, pp. 195-197, 2009.

[27] M. Steinhart, R. B. Wehrspohn, U. Gösele, and J. H. Wendorff, "Nanotubes by template wetting: a modular assembly system," Angewandte Chemie, vol. 43, no. 11, pp. 1334-1344, 2004.

[28] C. Rice, S. Ha, R. I. Masel, P. Waszczuk, A. Wieckowski, and T. Barnard, "Direct formic acid fuel cells," Journal of Power Sources, vol. 111, no. 1, pp. 83-89, 2002.

[29] C. Rice, S. Ha, R. I. Masel, and A. Wieckowski, "Catalysts for direct formic acid fuel cells," Journal of Power Sources, vol. 115, no. 2, pp. 229-235, 2003.

[30] X. Yu and P. G. Pickup, "Recent advances in direct formic acid fuel cells (DFAFC)," Journal of Power Sources, vol. 182, no. 1, pp. 124-132, 2008.
[31] Y. Zhu, S. Y. Ha, and R. I. Masel, "High power density direct formic acid fuel cells," Journal of Power Sources, vol. 130, no. 1-2, pp. 8-14, 2004.

[32] J. Giner, "The anodic oxidation of methanol and formic acid and the reductive. Adsorption of $\mathrm{CO}_{2}$," Electrochimica Acta, vol. 9, no. 1, pp. 63-77, 1964.

[33] A. Capon and R. Parsons, "The oxidation of formic acid on noble metal electrodes II. A comparison of the behaviour of pure electrodes," Journal of Electroanalytical Chemistry, vol. 44, no. 2, pp. 239-254, 1973.

[34] K. Kunimatsu, "Infrared spectroscopic study of methanol and formic acid adsorbates on a platinum electrode, part I: comparison of the infrared absorption intensities of linear $\mathrm{CO}(\mathrm{a})$ derived from $\mathrm{CO}, \mathrm{CH}_{3} \mathrm{OH}$ and $\mathrm{HCOOH}$," Journal of Electroanalytical Chemistry and Interfacial Electrochemistry, vol. 213, no. 1, pp. 149-157, 1986.

[35] D. S. Corrigan and M. J. Weaver, "Mechanisms of formic acid, methanol, and carbon monoxide electrooxidation at platinum as examined by single potential alteration infrared spectroscopy," Journal of Electroanalytical Chemistry, vol. 241, no. 1-2, pp. 143-162, 1988.

[36] R. Parsons and T. VanderNoot, "The oxidation of small organic molecules. A survey of recent fuel cell related research," Journal of Electroanalytical Chemistry, vol. 257, no. 1-2, pp. 9-45, 1988.

[37] R. S. Jayashree, J. S. Spendelow, J. Yeom, C. Rastogi, M. A. Shannon, and P. J. A. Kenis, "Characterization and application of electrodeposited $\mathrm{Pt}, \mathrm{Pt} / \mathrm{Pd}$, and $\mathrm{Pd}$ catalyst structures for direct formic acid micro fuel cells," Electrochimica Acta, vol. 50, no. 24, pp. 4674-4682, 2005.

[38] S. L. Gojković and T. R. Vidaković, "Methanol oxidation on an ink type electrode using Pt supported on high area carbons," Electrochimica Acta, vol. 47, no. 4, pp. 633-642, 2001.

[39] D. T. Sawyer, A. Sobkowiak, J. Julian, and L. Roberts, Electrochemistry for Chemists, John Wiley \& Sons, New York, NY, USA, 2nd edition, 1995.

[40] G. Q. Lu, A. Crown, and A. Wieckowski, "Formic acid decomposition on polycrystalline platinum and palladized platinum electrodes," Journal of Physical Chemistry B, vol. 103, no. 44, pp. 9700-9711, 1999.

[41] L. Palaikis and A. Wieckowski, "A catalytic study of formic acid oxidation on preferentially oriented platinum electrodes," Catalysis Letters, vol. 3, no. 2, pp. 143-158, 1989.

[42] W. Chen, J. Kim, S. Sun, and S. Chen, "Composition effects of FePt alloy nanoparticles on the electro-oxidation of formic acid," Langmuir, vol. 23, no. 22, pp. 11303-11310, 2007. 

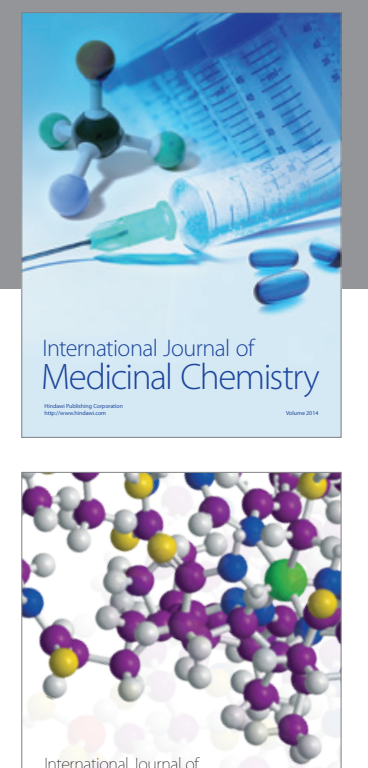

\section{Carbohydrate} Chemistry

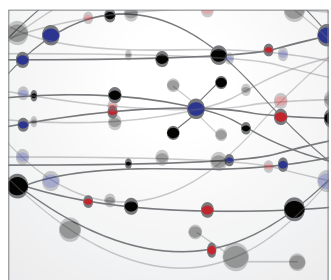

The Scientific World Journal
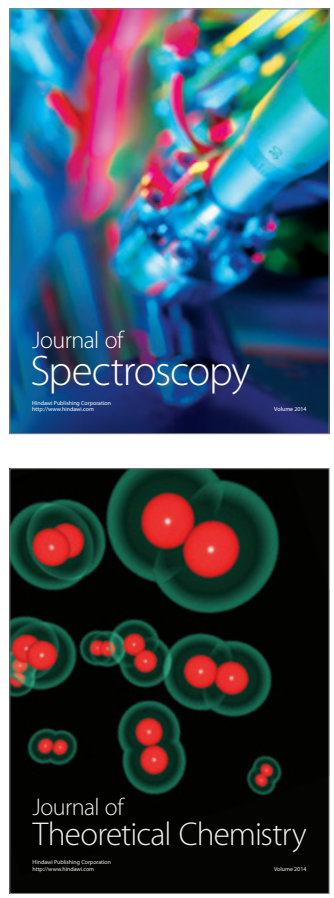
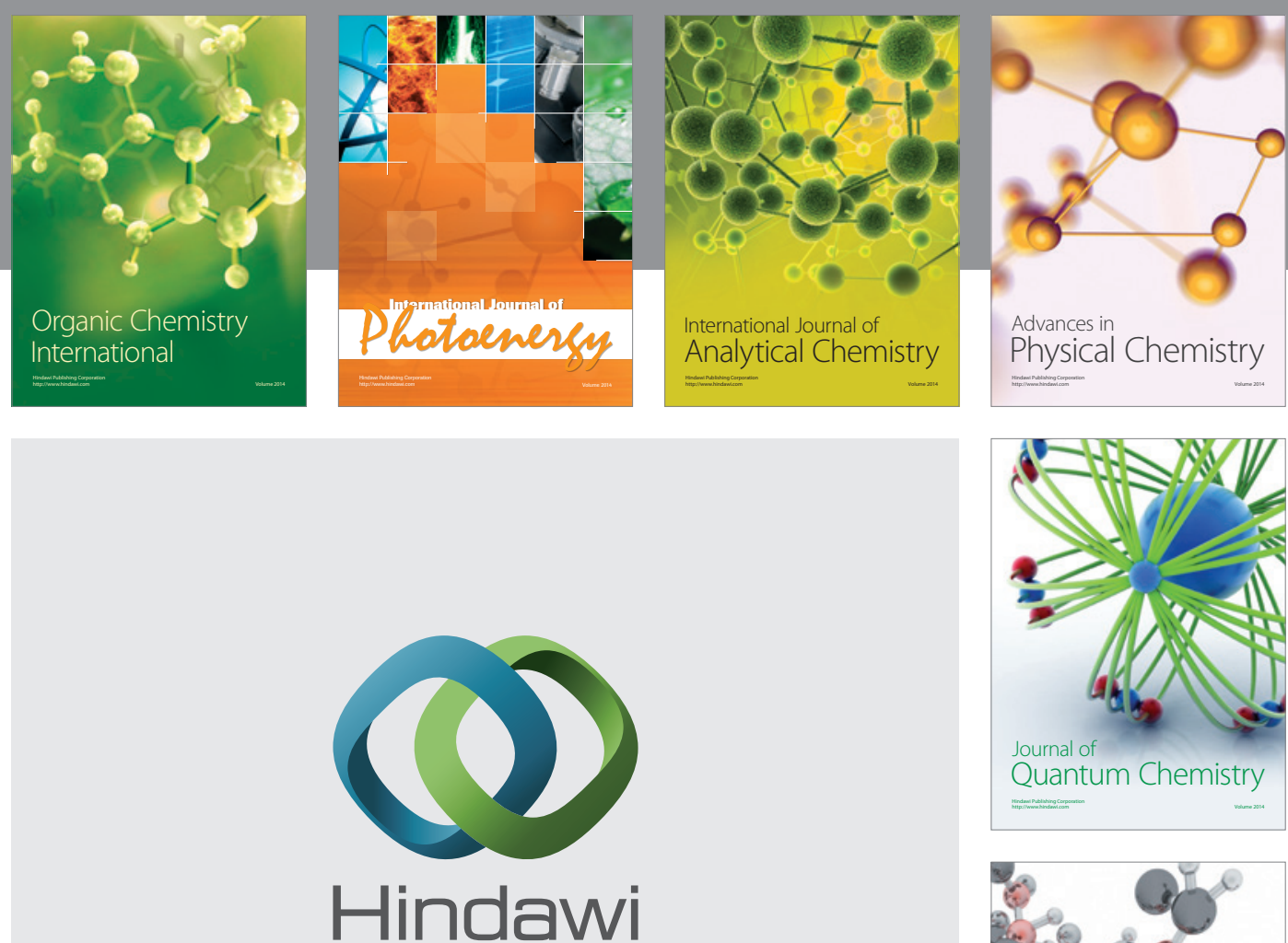

Submit your manuscripts at

http://www.hindawi.com

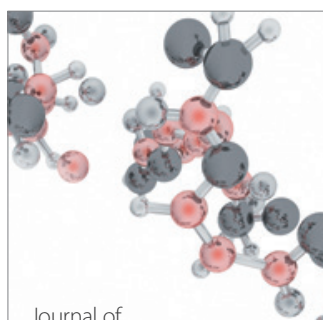

Analytical Methods

in Chemistry

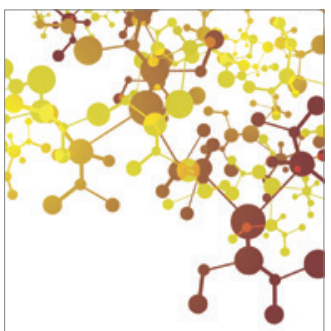

Journal of

Applied Chemistry

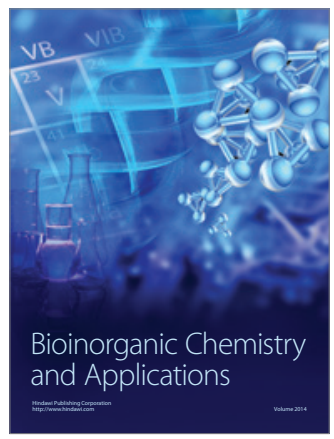

Inorganic Chemistry
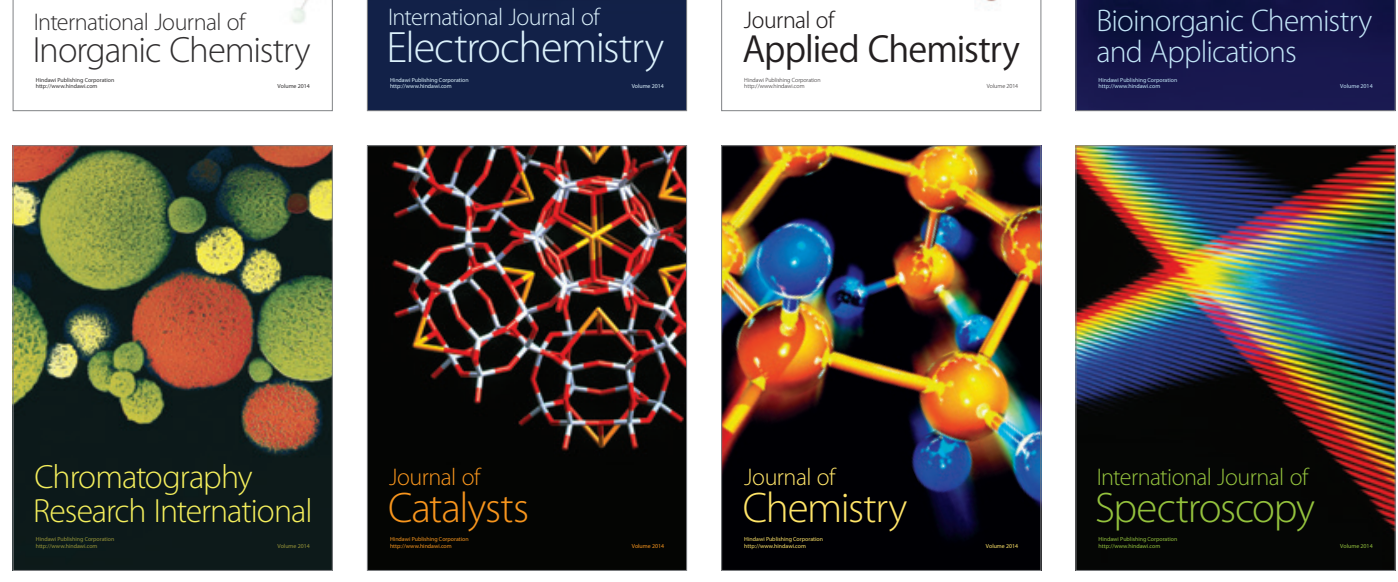